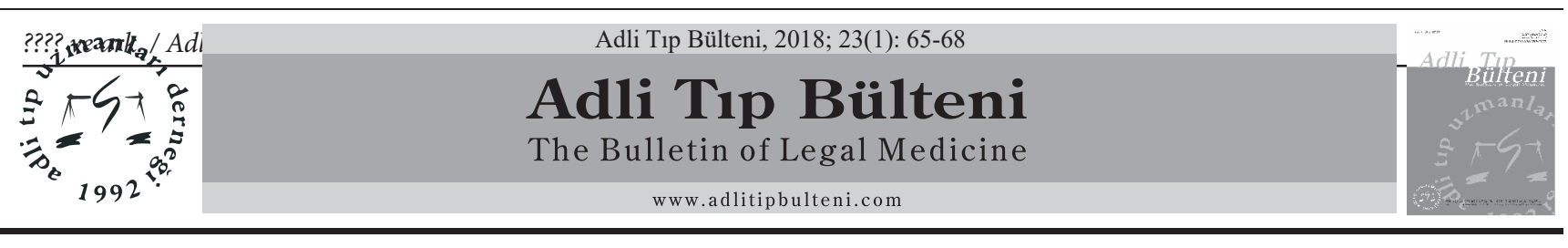

\title{
Tıbbi Uygulama Hatası İddialarının Değerlendirilmesinde Örnek Bir Sistem Hatası Olgusu
}

\author{
An Example Case of System Error in Evaluation of Medical Malpractice \\ Mahmut Şerif Yıldırım ${ }^{1}$, Aysun Balseven Odabaşıl ${ }^{1}$, Çetin Köse², Aykut Lale ${ }^{1}$, Ali Rıza Tümerl \\ ${ }^{1}$ Hacettepe Üniversitesi Tıp Fakültesi Adli Tıp Anabilim Dalı, Ankara \\ ${ }^{2}$ Adli Tıp Kurumu, Diyarbakır Adli Tıp Şube Müdürlüğ̈̈, Diyarbakır
}

\section{Özet}

The Joint Commission on Accreditation of Healthcare Organizations (JCAHO) tarafindan "sağlık hizmeti sunan bir profesyonelin uygunsuz ve etik olmayan bir davranışı sonucunda veya mesleki uygulamalarda yetersiz ve özensiz davranması sonucunda hastanın zarar görmesi” şeklinde tanımlanan "tıbbi malpraktis", uygulamada kullanımı ile "tıbbi uygulama hatası" kavramı ve bu yönde yapılan değerlendirmeler çoğunlukla hekim ya da sağlık çalışanının uygulamasına yönelik bir değerlendirme olup, değerlendirmenin içeriği sistem analizini kapsamamaktadır. Bu olgu sunumunda sistem hatası nedeni ile ölümle sonuçlanmış bir olgunun adli tıbbi değerlendirmesinde sistem hatası değerlendirmesinin yapılmasının gerekliliğine Adli Tıp uzmanlarının dikkatinin çekilmesi amaçlanmıştır.

Canlı donörden renal transplant yapılan 20 yaşındaki erkek olgu akut akselere rejeksiyon sonucunda greft nefrektomi ameliyatı geçirmiştir. Postoperatif süreçte kardiyak yüklenme bulguları olan olgu hastanede diyaliz ünitesinin açık olmaması nedeni ile özel bir merkeze acil diyaliz için gönderildiği sırada arrest olmuştur. Nakil ambulansında işler durumda oksijen kaynăğ olmadığı için aktif havalandırılamayan olgu yoğun bakımda tedavi altında iken vefat etmiştir. Yapılan değerlendirmede ölümde sistem hatası olması nedeni ile idarenin kusurlu olduğu kanaatine varılmıştır.

Tıbbi uygulama hataları konusunda kendisinden görüş istenen bilirkişilerin sistem hatalarını göz önünde bulundurması ve tıbbi uygulama hatalarını sadece sağlık çalışanı açısından değerlendirmek yerine sistem hatalarını da kapsayacak bir değerlendirme yapmaları esastır.

Anahtar Kelimeler: Klinik Adli Tıp; Tıbbi Uygulama Hatası; Sistem Hatas1.

\begin{abstract}
Medical malpractice, which is defined as "patients' harm resulting from healthcare professionals' improper and unethical attitude or insufficient and sloppy practice", is strictly limited to healthcare professionals' errors in practice. However, it should include system error analysis. In this article, a missed case of system error resulted in death is presented to remind the concept to Forensic Medicine experts and review the literature.

A 20-year-old male who underwent renal transplantation from a live donor, underwent graft nephrectomy due to acute accelerated rejection. The patient with cardiac overload findings in the postoperative period, collapsed while the patient was being sent to a special center for urgent dialysis due to lack of functional dialysis unit. In the transfer ambulance, there was no oxygen source and the patient was unable to actively ventilate. The patient died while under intensive care. In our evaluation, system error has been detected and the administration was held responsible.

The experts who are asked about the medical malpractice have to take the basic concept of "medical error" as a basis for considering the mistakes of medical applications not only from the point of view of health professionals.
\end{abstract}

Keywords: Clinical Forensic Medicine; Medical Malpractice; System Error.

\section{Giriș}

Tıbbi uygulama hatası veya diğer bir deyişle tıbbi malpraktis, The Joint Commission on Accreditation of Healthcare Organizations (JCAHO) tarafından "sağlık hizmeti sunan bir profesyonelin uygunsuz ve etik olmayan bir davranışı sonucunda veya mesleki uygulamalarda yetersiz ve özensiz davranması sonucunda hastanın zarar görmesi” şeklinde tanımlanmaktadır (1).

Sorumlu Yazar: Uzm. Dr. Mahmut Şerif Yıldırım

Hacettepe Üniversitesi Tip Fakültesi, Adli Tip Anabilim Dalı, Ankara

E-mail:dr.msyildirim@gmail.com

Geliş: 16.01.2017 Düzeltme: 09.08.2017 Kabul: 16.11.2017
Bir hastanın zarar görmesi sağlık çalışanının kendi hataS1, özensizliği veya bilgi ve beceri eksikliği sonucunda meydana gelebileceği gibi sağlık kurumunun veya sağlık düzenleyicilerinin kurmuş olduğu sistemin hatalı olmasından da kaynaklanabilmektedir (2). Ancak sistem hataları bazen tıbbi uygulama hatası iddialarını değerlendiren bilirkişilerin göz ardı ettikleri bir durum olarak karşımıza çıkmaktadır.

Ölümle sonuçlanmış ve açılan ilk dava hekim aleyhine sonuçlanmış bir tıbbi uygulama hatası iddiası olgusunun rücu davası sırasında Anabilim Dalımız tarafından değerlendirilmesi istenmiştir. Sistem hatası olduğu düşünülen bu olgu, sistem hatası kavramının literatür eşliğinde tartışılması ve konuya dikkat çekilmesi amacı ile sunulmuştur. 


\section{Olgu}

Öykü. Kronik böbrek yetmezliği tanısı ile canlı donörden greftle renal transplantasyon yapılmak üzere yatırılan ve opere edilen 20 yaşındaki erkek olgunun operasyon sonrasında genel durum bozukluğunun devam etmesi üzerine olgu yoğun bakımda yatırılmış, operasyon sonras1 3. günde rejeksiyon bulguları Doppler ultrasonografi ile tespit edilmiş ve donör böbreğinden yapılan biyopsinin histopatolojisi de greftin rejeksiyonu ile uyumlu bulunmuştur. Olgunun idrar miktarının $35 \mathrm{cc} /$ gün olması üzerine olguya greft nefrektomi yapılmış ve yeniden düzenli diyalize başlanmıştır. Greft nefrektomi operasyonu sonrasında 11. günde halen genel durum bozukluğu ve ağır anemi nedeni ile destek tedavisi görmekte olan olgunun servis nöbetçi hekimi tarafindan pulmoner ve kardiyak yüklenme bulgular1 tespit edilmiş olup acil diyaliz endikasyonu olduğu düşünülerek hasta diyalize yönlendirilmek istenmiştir. Olgunun bulunduğu hastanede diyaliz ünitesi bulunmasına rağmen hafta sonlarında çalıştırılmadığı için olgu anlaşmalı özel bir merkeze ambulans ile gönderilmiş ve diyalizine başlandığı sırada kardiyopulmoner arrest meydana gelmiştir. Diyaliz merkezinde ilk müdahalesi yapılan olgu yakındaki başka bir hastanenin yoğun bakım ünitesine nakledilmiştir. Bu nakil sırasında ambulansta oksijen tüpünün boş olması nedeni ile olgu oksijenize edilememiştir. Olgu bir gün sonra tekrar opere olduğu hastanenin yoğun bakım servisine nakledilmiş ve yatış süreci boyunca hiperkalemik ve asidotik olan olgu 9 günlük yoğun bakım tedavisi sonucunda resüsitasyona yanıtsız kardiyak arrest sonucu eksitus olarak kabul edilmiştir.

İlk dava süreci. Ailenin şikâyeti üzerine açılan davada verilen bilirkişi raporunda; günün nöbetçi hekimi olan pratisyen hekime diyaliz öncesi rutin kan biyokimyasal analizi yaptırmadığı ve biyokimya tetkikleri yapılıp hiperkalemi var ise önce buna yönelik tedbir alınmasının gerekliliği ifade edilerek kusur atfedilmiştir.

Üç farklı üniversiteden Adli Tıp, Üroloji ve Nefroloji uzmanları ile yapılan değerlendirme sonucunda; nöbetçi pratisyen hekimin transplantasyon ünitesinde nöbetçi olma yetkinliğinde olmadığı, post-transplantasyon yoğun bakım servislerinde ilgili branş hekiminin nöbetçi olmasının gerektiği ve bu nedenle idarenin kusurlu olduğu, nöbetçi hekimin acil diyaliz endikasyonunun yerinde olduğu, kardiyak yüklenme bulguları olan ve genel durumu ağırlaşmış olan olgunun biyokimya tetkiki beklenmeksizin diyalize alınmasının doğru olduğu (3, 4) ve acil durumlarda biyokimyasal tetkik yapılmasının da bilimsel olarak gerekli olmadığı (4), ayrıca hiperkalemi mevcut olsa dahi diyalizin de hiperkaleminin acil tedavi seçeneklerinden birisi olması nedeni ile (5) biyokimyasal tetkiklerin beklenmesinin kişinin acil durumu göz önüne alındığında yine gerekli olmadığı, bu nedenle nöbetçi hekime atfi kabil kusur bulunmadığı, 26.02.2001 tarih ve 1832 sayılı Bakanlık Oluru ile yürürlüğe girmiş olan Böbrek Nakli Merkezleri Yönetmeliği’nin 7. maddesinde; "Böbrek nakli yapılacak merkezlerde diyaliz merkezi olması gerektiği, hastanede diyaliz merkezi bulunmuyor ise 18/06/2010 tarihli ve 27615 say1lı Resmi Gazete'de yayımlanan Diyaliz Merkezleri Hakkında Yönetmeliğe uygun olarak kurulmuş en az iki adet hemodiyaliz cihazı bulunması gerektiğì" belirtilmiş olup, her ne kadar söz konusu hastanede diyaliz merkezi bulunuyor ise de sürekli faal olmamasının bilimsel gerçeklere ve ilgili yönetmeliğe aykırı olduğu ve idarenin kusurunun bulunduğu, olgunun naklinde kullanılan ambulansta oksijen tüpünün boş olmasının, kardiyak yüklenme bulguları olan ve bu denli sıkışıklığı olan bir olgu açısından ehemmiyeti göz önüne alındığında, ambulanslarda gerekli şartları sağlamaması nedeni ile de idarenin kusuru olduğu kanaatine varılmış ve sonuç olarak; idarenin kurmuş olduğu sistemde ve sistemin denetlenmesinde kusurlarının olduğu, daha önce kusur yüklenmiş olan hekimin kusurunun olmadığı kanaatinin oluştuğu yönünde raporlanmıştır.

\section{Tartışma}

Yabancı literatüre bakıldığında tıbbi uygulama hatası kavramının bir üst basamağı olarak tıbbi hata kavramının yer aldığı görülmektedir. Tıbbi hata kavramı ve tıbbi uygulama hataları dışındaki hastanın zarar görmesine neden olan durumlar ise ülkemizde yapılan yayınlar arasında çok nadiren değinilen konular olarak karşımıza çıkmaktadır. Tıbbi hata kavramının alt başlıklarından birisi olan tıbbi uygulama hataları veya diğer bir deyişle tıbbi malpraktis sadece sınırlı bir etkiye sahiptir (6-8).

Yine Amerika Birleşik Devletleri ve Avrupa kaynaklı yayınlara bakıldığında tıbbi hata kavramı tıbbi uygulama hatalarının üst çatısı olarak bahsedilmediği yayınlarda bile sistem hatası veya ekipman hatası gibi kavramlar kullanılmakta ve bunlar sağlık çalışanlarının sorumluluk alanı dışında değerlendirilmektedir $(9,10)$.

Tıbbi hatalar araştırılırken çok sık yapılan bir hata sadece sağlık çalışanının kusurunun olup olmadığının araştırılmasıdır. Oysaki tıbbi hatalar sadece sağlık çal1şanlarının tıbbi uygulama hataları sonucunda meydana gelmemektedir. Tibbi uygulamalar sırasında sistemdeki sorunlar ve ekipman sorunları da sağlık hizmeti alanların zarar görmesine neden olabilmekte ve bu zararların büyük bir kısmı ise idarenin kendi kusurlarını telafi etmesi ile önlenebilmektedir (9-12). 
Sistem hatası tıbbi hata kavramının ayrılmaz bir parçasıdır. Sistem hatasının en büyük bileşenleri ise literatürde denetim sorunları ve iş yükünün fazlalığı olarak belirtilmektedir (13-15). İş yükünün fazlalığı hem hizmet kalitesini düşürmekte hem de bazı şartlar altında yetkin olmayan personelin komplike hastaya müdahale etmesine neden olabilmektedir. Aynı zamanda özellikle yoğun bakım şartlarında daha sık muayene ve takibinin yapılmasının gerektiği olgularda personel yetersizliği özellikle sorun oluşturmaktadır. Personel yetersizliği olgumuzda olduğu gibi hem yoğun bakım ünitesinde yetkinliği olmayan hekimin nöbetçi olarak bırakılmasına neden olabileceği gibi yine olgumuzda olduğu şekli ile diyaliz ünitesinde çalışan personel sayısının azlığı nedeni ile hafta sonlarında hizmet verilmemesine neden olabilmektedir. Her iki durum da idarenin gerek eğitimli personel sayısı$\mathrm{n} 1$ artırarak, gerekse de mevcut personeli daha akılcı bir yaklaşımla dağıtarak üstesinden gelebileceği durumlar olarak dikkati çekmektedir.

Çalışma şartları, iş zamanlaması, iş üretiminin artırılması için yapılan baskı ve iş üzerindeki kontrolün kaybı tıbbi hata yapılmasına yatkınlık oluşturmaktadır $(6,15)$. Ülkemizde hekim sayısının yetersizliği ve hekimlerin iş yükünün çok olması bu hataların kolaylıkla ortaya çıkabilmesine yol açarken sistem hatasının bu yönü birçok olguda göz ardı edilmektedir. Oysa malpraktis olguları değerlendirilirken hekimin o sırada bulunduğu ortam tüm ayrıntıları ile gözden geçirilmeli ve insan doğasının ve kognitif sürecin bir parçası olarak sistem hatalarının herkesi yanlış değerlendirme veya müdahaleye itebileceği akıldan çıkarılmamalıdır.

Personel yetersizliği ve iş yükünün fazlalığı hasta sağlığına da dramatik etkilerde bulunmaktadır. Hayward ve Hofer'in çalışmasında (14) ölümle sonuçlanan tıbbi hataların \%23'lük diliminde iş yükü sorumlu tutulmuş ve iş yükünün azaltılması ile ölümlerin önüne geçilebileceği ifade edilmiştir. Hekimin hastaya ayırdığı sürenin yetersizliği ve yardımcı sağlık personel sayısının azlığı gibi iş yükünü artıran hususlar hem hekimler hem de sağlık hizmeti alan kişiler arasında tıbbi hataların en sık nedenleri olarak görülmektedir (16).

Personel eksikliği, ekipman yetersizliği, eğitim sorunları gibi birçok idareye ait kusur dünya geneline baktığımızda tüm tıbbi hataların en az üçte birlik kısmını oluşturmakta iken (14); ülkemizde idare kusuru sadece $\% 2,3$ oranında raporlanmaktadır (17). Bu durum, görüş istenen bilirkişilerin tıbbi hata nedenlerini sistematik olarak değerlendirmemelerinden kaynaklanabileceği gibi; görüş isteğinde bulunan Hakim ve Savcıların, bilirkişilere çoğunlukla, doğrudan sağlık çalışanlarının kusur durumlarını sormalarından da kaynaklanabileceği düşünülmektedir.
Sistem hatasının yol açtı̆̆ önemli kusurlardan birisi olan ekipman yetersizliği de bu olguda dikkati çekmektedir. Olgunun nakledildiği ambulansta kullanılabilir durumda bir oksijen tüpünün olmaması kardiyovasküler arrest sonrası yoğun bakıma yetiştirilmeye çalışılan olgunun hipoksik kalmasına neden olabileceği ve bu durumun ölümde katkısının bulunabileceği yadsınamaz bir gerçekliktir.

\section{Sonuç}

Tıbbi uygulama hataları konusunda kendisinden görüş istenen bilirkişilerin sistem hatalarını göz önünde bulundurması ve tıbbi uygulama hatalarını sadece sağlık çalışanı açısından değerlendirmek yerine "tıbbi hata" temel kavramı ve bu kavramın bileşenlerini gözden geçirerek değerlendirmesi gerektiği gibi tıbbi uygulama hatası iddiasını değerlendirilecek bilirkişilere dosya gönderimi sırasında da sadece ilgili olayda hekimin kusurunun olup olmadığı değil, sistem hatası ve olayın diğer bileşenlerini de kapsayacak bir araştırma yapılmasını sağlayacak şekilde bilirkişilerden olayın değerlendirilmesinin istenmesi sağlanmalıdır. Sağlık çalışanlarının kusur durumları değerlendirilirken; işler bir sistemin yokluğu veya sistemden ve genel işleyişten kaynaklanan olumsuzluklar, içinde bulunulan çalışma şartlarının güçlüğü, sağlık çalışanının çalıştığı kurumda mevcut olan imkânların azlığı ve sağlık çalışanının yetkin olduğu alan dışında görevlendirilip görevlendirilmediği gibi faktörler de gözden geçirilmelidir.

\section{Kaynaklar}

1. JCAHO. Sentinel Event Statistics 2006 [cited 2016 14.07]. Available from: www.jointcommission.org/Library/TM Physicians/Tmp_11_06.Htm.

2. Bernstein M, Hebert PC, Etchells E. Patient safety in neurosurgery: detection of errors, prevention of errors, and disclosure of errors. Neurosurgery Quarterly. 2003;13(2):12537. doi:10.1097/00013414-200306000-00008

3. Hakim RM, Lazarus JM. Initiation of dialysis. Journal of the American Society of Nephrology. 1995;6(5):1319-28.

4. Clark JE, Soricelli RR. Indications for Dialysis. The Medical clinics of North America. 1965;49:1213-39.

5. Greenberg A, editor Hyperkalemia: treatment options. Seminars in Nephrology; 1998.

6. SA M. The individual, the system, and medical error. 2003.

7. Rothschild JM, Landrigan CP, Cronin JW, Kaushal R, Lockley SW, Burdick E, et al. The Critical Care Safety Study: The incidence and nature of adverse events and serious medical errors in intensive care. Critical care medicine. 2005;33(8):1694-700.

8. Chiozza ML, Ponzetti C. FMEA: a model for reducing medical errors. Clinica Chimica Acta. 2009;404(1):75-8. 
9. Bhasale AL, Miller GC, Reid SE, Britt HC. Analysing potential harm in Australian general practice: an incident-monitoring study. Medical Journal of Australia. 1998;169(2):73-6.

10. McDonald CJ, Weiner M, Hui SL. Deaths due to medical errors are exaggerated in Institute of Medicine report. Jama. 2000;284(1):93-5.

11. Dovey S, Meyers D, Phillips R, Green L, Fryer G, Galliher $\mathrm{J}$, et al. A preliminary taxonomy of medical errors in family practice. Quality and safety in health care. 2002;11(3):2338.

12. Güzel S, Yavuz MS, Aşırdizer M. Adlî Tıp Kurumu İhtisas Kurulları ile Yüksek Sağlık Şurası Raporları Arasında Çelişki Bulunan ve Adli Tıp Genel Kurulu'nda Görüşülen Malpraktis Olgularının İrdelenmesi. The Bulletin of Legal Medicine, 2002;7(1):14-20.

13. Kachalia A, Gandhi TK, Puopolo AL, Yoon C, Thomas EJ, Griffey R, et al. Missed and delayed diagnoses in the emer- gency department: a study of closed malpractice claims from 4 liability insurers. Annals of emergency medicine. 2007;49(2):196-205.

14. Hayward RA, Hofer TP. Estimating hospital deaths due to medical errors: preventability is in the eye of the reviewer. Jama. 2001;286(4):415-20.

15. Landrigan CP, Rothschild JM, Cronin JW, Kaushal R, Burdick E, Katz JT, et al. Effect of reducing interns' work hours on serious medical errors in intensive care units. New England Journal of Medicine. 2004;351(18):1838-48.

16. Blendon RJ, DesRoches CM, Brodie M, Benson JM, Rosen $\mathrm{AB}$, Schneider E, et al. Views of practicing physicians and the public on medical errors. New England Journal of Medicine. 2002

17. Karpuz, Hakan. (2015) Kardiyovasküler Hastalıklar ile ilgili Kusurlu Tıbbi Uygulamalar. İstanbul Üniversitesi Adli Tıp Enstitüsü, Doktora Tezi. İstanbul.;347(24):1933-40. 